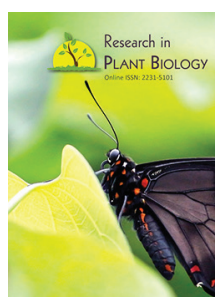

ISSN: 2231-5101
Received: January 19, 2018 Accepted: April 10, 2018 Published: April 19, 2018

*Corresponding Author: Bokary Allaye Kelly Email: bokarykelly@gmail.com

\section{Variation of Vitellaria paradoxa phenophases along the north-south gradient in Mali}

\author{
Bokary Allaye Kelly ${ }^{1 *}$, Mahesh Poudyal'2, Jean-Marc Bouvet ${ }^{3}$ \\ 'Institut d'Economie Rurale, Programme Ressources Forestières, Centre Régional de la Recherche Agronomique \\ de Sikasso, BP 178 Sikasso, Mali. ${ }^{2}$ Ecosystem Services for Poverty Alleviation (ESPA) Programme, Argyle House, 3 \\ Lady Lawson St., Level D, Edinburgh EH3 9DR, United Kingdom, ${ }^{3}$ Cirad Forestry Department, "Genetic diversity \\ and breeding of forest tree species" research unit, Campus International de Baillarguet, TA 10C, BP 5035, 34035 \\ Montpellier, France
}

\begin{abstract}
We monitored flowering, fruiting and leafing of Vitellaria paradoxa (shea tree) along the north-south gradient in Mali (West Africa), using three study sites for a period of three years. In each site, adult shea trees were marked and monitored in permanent plots of both field and fallow stands. The chronology of phenophases and their mean length as well as flowering and fruiting were assessed. Our data revealed significant variation according to site and stand. The onset of events starts earlier in the south than in the centre or north, but the period covered by events was almost the same for all sites ( 3 to 6 months for flowering; 5 to 6 months for fruiting; and 2 to 4 months before full leafing). Flowering and fruiting were more regular in the south, but often as high in the north, with an almost similar trend in both fields and fallows. In the centre, flowering was also high in fields as well as in fallows, while the fruiting was medium to high. We also observed variations in the mean length of phenological events in study sites and stands. Sites in the south showed the highest average length of flowering and leafing ( 76 days and 44 days, respectively), while the central site showed the greatest length of mean fruiting (110 days). We observed a significant site*stand interaction and noticeable variation over the years. Our study indicates that phenological events of shea tree could be influenced by several interacting biotic and abiotic factors. A future research challenge in shea phenology would be to discriminate these factors and thus help sustainable management of shea tree parklands.
\end{abstract}

KEYWORDS: Climatic gradient, fallow, field, phenology, shea tree, west africa

\section{INTRODUCTION}

Ecosystems in general have come under considerable pressure due to changing climate. The ecosystems of West African savannas have been particularly affected since the severe drought in the early 1970s. Plants and animals in these ecosystems have to develop mechanisms of adaptation to environmental conditions [1]. It has also been stated that certain patterns in plant availability, as well as the various phases of plant development, could be directly related with environmental factors like temperature and rainfall [2].

Adaptation mechanisms could be studied in the functional rhythms of plants and plant communities. Authors have further pointed out that the phenology of flowering and their relation to abiotic factors [3,4]. According to Leith [5], phenology is 'the study of the timing of recurrent biological events, the causes of their timing with regard to biotic and abiotic forces, and the interrelation among phases of the same or different species'. Phenological studies are important for the conservation [6]. While the importance of understanding phenological patterns and variation, particularly in the context of global climatic change has been recognised [7], information on phenological patterns of tropical plants, particularly for woody plants, is still scarce [8].

Okullo et al. [6] have reported that formal studies of the reproductive processes and phenological patterns are vital in developing a viable strategy for conservation of forest tree

Copyright: $\odot 2018$ The authors. This article is open access and licensed under the terms of the Creative Commons Attribution License (http://creativecommons.org/licenses/by/4.0/) which permits unrestricted, use, distribution and reproduction in any medium, or format for any purpose, even commercially provided the work is properly cited. Attribution - You must give appropriate credit, provide a link to the license, and indicate if changes were made. 
species like Vitellaria paradoxa. Furthermore, they state that knowledge of the phenology of Vitellaria is necessary for managing the stands and collecting enough fruits, and for facilitating the regeneration needed to restore the age balance of the stands. Few studies have compared populations located at sites characterised by marked environmental differences [9]. This approach is, however, important since it could help us to understand the extent of phenological variability. This is particularly important for Vitellaria paradoxa, which covers a wide range of agro-ecological zones and faces several pressures, despite its economic and ecological importance. Many recent studies have highlighted the constraints the species is facing. Vitellaria is degrading in all countries where it occurs [10]. A drastic reduction of the Vitellaria population was observed in the Central Plateau of the southern part of Burkina Faso [11] and has been attributed to abiotic stresses and pathogens $[12,13]$.

Therefore, phenological studies over the range of this valuable resource as it faces such constraints are important. The aim of this study was to characterise species adaptation strategies developed according to climatic gradient through the variation of tree phenology in the natural populations of the Sudano-Sahelian zone.

\section{MATERIALS AND METHODS}

\section{Study Sites}

Three sites were selected following a north-south gradient using climatic index. These three sites were: Daelan (district of San) in the north, Mperesso (district of Koutiala) in the centre and Nafégué (district of Kadiolo) in the south (Figure 1). The weather data obtained from the meteorological stations closest to these sites show that the mean rainfall is $699 \mathrm{~mm}$ at San, $901 \mathrm{~mm}$ at Koutiala (over the last 21 years for the two stations) and $1040 \mathrm{~mm}$ at Kadiolo (over the last 13 years). The average number of rainy days over these periods was 59 days at San and

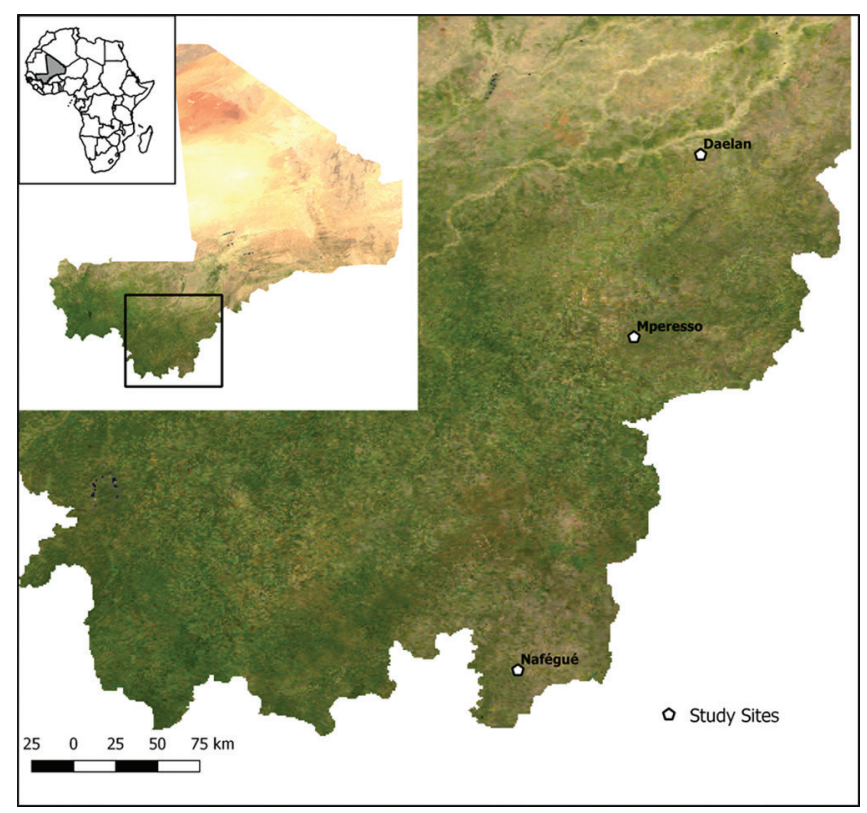

Figure 1: Map showing study sites along the north-south gradient
67 days at Kadiolo while the mean temperature was $39.83^{\circ} \mathrm{C}$ at $\mathrm{San}$ and $28.33^{\circ} \mathrm{C}$ at Koutiala. The geographical locations of these sites are shown on the map below.

\section{Experimental Design}

In each site, areas under two land use types, field and fallow, were covered by establishing permanent plots. For each land use type, we covered the three land-use ages based on the time the land has been under a given type of use. For both field and fallow, land-use ages were classified as follows:

New $(\mathrm{N})$ - the area under the land use type for $1-5$ years (e.g., field cultivated continuously for 1-5 years or the land left fallow continuously for $1-5$ years)

Medium (M) - the area under the land use type for 6-10 years

Old $(\mathrm{O})$ - the area under the land use type for more than 10 years

Three replicate permanent plots were established in each area of given age for each land use type, giving a total of 18 plots in each site (9for each type of land use).

\section{Establishing Permanent Plots}

The 18 permanent field plots were established in each site. The dimensions of each plot were $50 \mathrm{~m} \times 50 \mathrm{~m}(0.25 \mathrm{ha})$.

\section{Phenology Monitoring}

In each site, 60 individuals ( 10 trees per age class and per land use) giving a total of 180 shea trees across the three gradients were selected. These trees were marked and monitored for flowering, fruiting and leafing phenology based on their fruit production using the knowledge of local farmers. The monitoring was done every two weeks on these marked shea adult trees (DBH of $10 \mathrm{~cm}$ or greater).

The exact location of these adult trees was determined using GPS and their position was entered as geographic coordinates in a GIS database. Each adult tree had a unique identification number/code and was physically marked with spray paint.

\section{Recorded Variables}

\section{* Morphological traits}

The monitored adult trees were measured for their morphological traits. Recorded variables were:

- The diameter at $1.30 \mathrm{~m}$ above the ground (DBH),

- The total height,

- The crown size (north-south and east-west crown diameter)

\section{* Phenological variables}

"Flowering ability" was recorded as a categorical variable with only two values, 1 if the individual tree flowered and 0 if not. 
Four stages of flowering were described:

1. The "start of flowering": the appearance of the first buds of flowers,

2. The "flowering is going on": when first buds are opening, whereas others are appearing,

3. "Full flowering": most flowers are open,

4. "End of flowering": no more new flowers appear.

These stages allowed us to define a variable called "length of flowering" = period between 1 and 4 .

The same variables as for flowering were defined for fruiting i.e., "fruiting ability» and "length of fruiting". The defined fruiting phases were:

1. "Start of fruiting": fruit setting,

2. "Development of fruits": fruits are being developed (increasing in size)

3. "Physiological maturity": presence of full-size green fruits

4. "Full maturity": presence of yellowish-brown fruits fallen and/or harvested.

The "Length of fruiting" = period between 1 and 4 .

The leafing phases were:

1. "Start of leafing": swelling of leaf buds,

2. "Leafing is going on": from buds break to most leaves expanded

3. "Full leafing": all leaves are green and expanded

4. "Start of leaf shedding" some leaves started changing colour from green to greenish yellow/yellowish brown and dropping.

The variable defined for the leafing was the "length of leafing" $=$ period between 1 and 3 .

\section{Data Analysis}

Data were analysed using SYSTAT 9 for Windows. Descriptive statistics were computed as well as an analysis of variance to test the significance of site, land-use type (field, fallow) and age of land use (new, medium, old) for growth and phenological data.

\section{RESULTS}

\section{Morphological Traits of Monitored Individuals}

The results of morphological traits measurements over two years (2007 and 2009) are shown in Figure 2 - (a) for field stands and (b) for fallow stands.

For the DBH, the stand "site interaction was not significant. Sites were significantly different over all stands. The site of Nafégué in the south displayed the lowest mean DBH $(26.05 \mathrm{~cm})$; significantly lower than those of the sites of Daelan in the north $(30.71 \mathrm{~cm})$ and Mperesso in the centre $(31.35 \mathrm{~cm})$. The means of these last two sites were not significantly different. The year effect was not significant and the mean annual increment of diameter was low $(0.74 \mathrm{~cm})$. Stands were also significantly different over all sites. Fallows displayed the highest mean compared to fields $(30.46 \mathrm{~cm}$ vs. $28.27 \mathrm{~cm})$.

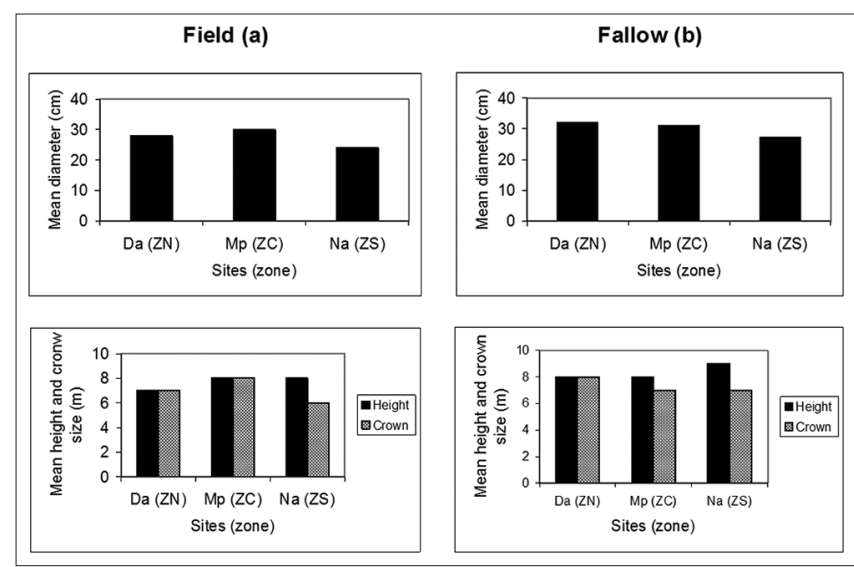

Figure 2: Mean diameter, height and crown size of monitored shea trees per stand and site

Over all stands of shea trees, the site of Daelan displayed the lowest mean height $(7.89 \mathrm{~m})$, which was significantly lower than those of the sites of Mperesso $(8.82 \mathrm{~m})$ and Nafégué $(9.07 \mathrm{~m})$. The latter two did not differ significantly. Stands did not differ significantly, but the stand"site interaction was significant $(\mathrm{P}=0.011)$. Mean annual increment for height growth was $45 \mathrm{~cm}$.

Between-site differences in crown size as well as between-year differences were significant over all stands, but the difference between stands and the stand ${ }^{*}$ site interaction were not significant. Mean annual increment for crown size was $24 \mathrm{~cm}$.

\section{Chronology of Flowering And Fruiting of Vitellaria Paradoxa}

Figure 3 shows the diagrams of flowering and fruiting (all age classes combined), indicating periods covered by the flowering and fruiting according to stands for each site. We can observe from these diagrams that when the study started in February 2008, flowering was already going on in all sites.

\section{Flowering and Fruiting at Daelan (North Sudanian Zone)}

In the northern site (Daelan, Fig.3a), flowering generally starts in January and ends in May, with a peak (full flowering) from March to April. There were some between- and within-year variations; variations were observed according to stand too. In 2009, flowering appeared to be more regular in field stands compared to fallow stands and it spread over 3 to 6 months.

Fruiting appeared to be a highly year-dependent phenological event (no monitoring in 2009 because of bad fruiting). Generally, it starts in March while the flowering is at its peak. Often, according to year, it can start earlier (February). It covers a period of 5 to 6 months from the start to fruit ripeness in July. Physical maturity (full-sized fruits) occurred from May (April some years) to June and harvesting occurred from July (June some years) to August. There was no evident difference between stands. 


\section{Flowering and Fruiting at Mperesso (South Sudanian Zone)}

In the centre site (Mperesso, Fig. 3b), flowering generally starts in January and ends in April/May (according to the year) with a peak (full flowering) from February to March or March to April. There are some variations according to the year in terms of period covered by flowering events with shifting peaks. There is no evidence of variation according to stand.

Fruiting started in March at the peak of flowering and covered a period of 5 to 6 months (March - August or June some years). Physical maturity occurred from June to July or May to June (depending on the year). Harvesting occurred from June/July to August/September depending on the stand. The fruiting trend (not monitored in 2010) was similar for both stands.

\section{Flowering and Fruiting At Nafégué (North Guinean Zone)}

In the southern site (Nafégué, Figure.3c), flowering generally starts in November or December of the preceding year (even earlier some years for precocious individuals) and ends in March or April. The peak of flowering is January/February to March in some years. There was no evident difference between stands in 2009, but in 2010 some variations were observed.

Fruiting in this site started in December of the preceding year or in January of the current year at the peak of flowering. Some variations were observed according to the year and stand, but there was no evident difference in the trend. Physical maturity occurred generally from March to April and full maturity of fruits occurred in May or June according to the stand and year. Harvesting period varies according to year, but is usually between April and July.

Table 1: Proportion of shea trees having flowered and fruited per year and per stand by site

\begin{tabular}{llccc|cccc}
\hline & \multicolumn{3}{c|}{$\%$ of shea trees having flowered } & & \multicolumn{3}{c}{$\%$ of shea trees having fruited } \\
\hline Stands & Sites & 2008 & 2009 & 2010 & & 2008 & 2009 & 2010 \\
\hline Fields & Daelan & 100 & 47 & 100 & & 100 & 33 & 100 \\
& Mperesso & 97 & 87 & 100 & 83 & 53 & \\
& Nafégué & 100 & 97 & 100 & & 100 & 97 & 100 \\
\hline \multirow{2}{*}{ Fallows } & Daelan & 93 & 30 & 90 & & 93 & 30 & 90 \\
& Mperesso & 100 & 70 & 80 & & 90 & 27 & \\
& Nafégué & 97 & 93 & 93 & & 97 & 93 & 90 \\
\hline
\end{tabular}

\section{Ability of Flowering and Fruiting of Vitellaria Paradoxa}

The percentage of shea trees having flowered and fruited in each site during monitoring period is displayed in Table 1.

The northern site (Daelan) had a high level of flowering in 2008 and 2010 in field stands (Table 1), unlike in 2009 when the level of flowering dropped $(47 \%)$ and the level of fruiting followed the same trend. The trend observed for fallows was close to that in the fields at this site.

The centre site (Mperesso) also had a high proportion of individuals having flowered in 2008 and 2010 in field stands. The level of fruiting (not monitored in this site in 2010), was low, particularly in 2009. The trend displayed in fallows was similar to that displayed in fields, but fallows showed a lower level of flowering in 2009 and 2010 and a very low level of fruiting in 2009 (Table 1). It appears from Table 1 that, in the southern site (Nafégué), a high proportion of individuals flowered and fruited in all stands in all years monitored. High harmony between flowering and fruiting was also observed in this site.

\section{Length of Phenological Events (Flowering, Fruiting and Leafing)}

The means of the length of phenological events over the monitoring period are shown in Table 2.

From Table 2, for all stands combined, we see that the site of Nafégué (zone south) showed the highest mean for flowering length (76 days), which was significantly longer than those of the other sites, which showed the same mean (68 days), and the highest mean for leafing length was not statistically different from that of Daelan (zone north). The site of Mperesso (centre) showed the highest mean for fruiting length (110 days), which was significantly longer than those of the other sites, and Nafégué showed the lowest mean of fruiting length (86 days). However, the site of Mperesso showed the lowest mean for leafing length (36 days), which was significantly lower than the means of the other sites.

Furthermore, for all sites combined, field and fallow stands displayed almost the same mean for flowering length and the

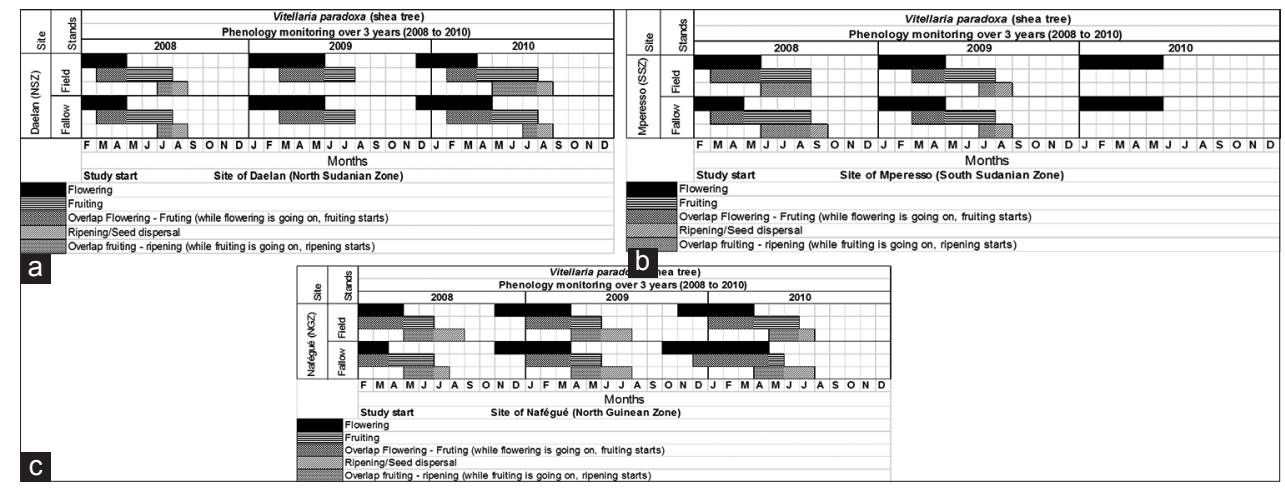

Figure 3: (a) Phenogram of flowering and fruiting at Daelan (north Sudanian zone), (b) Phenogram of flowering and fruiting at Mperesso (south Sudanian zone), (c) Phenogram of flowering and fruiting at Nafégué (north Guinean zone) 
same mean for fruiting length, but were significantly different regarding leafing length (Table 2). The mean leafing length of fallow stands (42 days) was longer than that of field stands (39 days). The site ${ }^{*}$ stand interaction was significant for all variables. Fallow stands at Nafégué showed the highest mean for flowering and leafing length, and fallow stands at Mperesso showed the highest mean for fruiting length (Table 2).

Within the stand at each site, some variations were observed in the length of phenological events according to the year (Table 3). At Daelan (north), the highest means of flowering length were observed in 2010 for both field and fallow stands in an increasing pattern from 2008 to 2010 . A similar pattern was observed at Mperesso (zone centre). At Nafégué (south), the highest mean of flowering length for field stands was observed in 2009. For fallow stands, the means of flowering were almost the same in 2009 and 2010, and much higher than that observed in 2008. The highest means of fruiting length were observed in 2010 for both field and fallow stands at Daelan and at Nafégué. At Mperesso, the highest means of fruiting length were observed in 2018 for both field and fallow stands, fruiting not being monitored at that site in 2010 (Table 3).

Table 2: Mean length of flowering, fruiting and leafing per site, per stand and per site* stand interaction over 3 years of monitoring. Coefficients of variation (\%) are indicated in brackets

\begin{tabular}{|c|c|c|c|}
\hline \multicolumn{4}{|c|}{ Mean lengths of phenological events (in number of days) } \\
\hline & Flowering & Fruiting & Leafing \\
\hline \multicolumn{4}{|c|}{ Sites (over all stands) } \\
\hline Daelan & $68(27)$ & $102(13)$ & $42(23)$ \\
\hline Mperesso & $68(26)$ & $110(12)$ & $36(28)$ \\
\hline Nafégué & $76(21)$ & $86(24)$ & $44(33)$ \\
\hline \multicolumn{4}{|c|}{ Stands (over all sites) } \\
\hline Field & $70(25)$ & 97 (19) & $39(26)$ \\
\hline Fallow & $71(25)$ & $97(21)$ & $42(31)$ \\
\hline \multicolumn{4}{|c|}{ Stands by site } \\
\hline \multicolumn{4}{|c|}{ Daelan (north zone) } \\
\hline Field & $70(27)$ & $105(13)$ & $43(23)$ \\
\hline Fallow & $66(26)$ & $99(12)$ & $42(22)$ \\
\hline \multicolumn{4}{|c|}{ Mperesso (centre zone) } \\
\hline Field & $70(25)$ & $104(10)$ & $40(25)$ \\
\hline Fallow & $67(28)$ & $116(12)$ & $37(31)$ \\
\hline \multicolumn{4}{|c|}{ Nafégué (south zone) } \\
\hline Field & $72(24)$ & $86(22)$ & $39(28)$ \\
\hline Fallow & $80(16)$ & $87(26)$ & $48(32)$ \\
\hline
\end{tabular}

The highest means of leafing length were observed in 2009 for both field and fallow stands at Daelan. At Mperesso, the highest means of leafing length were observed in 2010 for both field and fallow stands. At Nafégué, the highest mean of leafing length was observed in 2010 for field stands while for fallow stands it was observed in 2009 (Table 3).

Legend: $\mathrm{Da}=$ Daelan (north zone) $\mathrm{Mp}=$ Mperesso (centre zone), $\mathrm{Na}=$ Nafégué (south zone)

Legend: $\mathrm{Da}=$ Daelan (north zone) $\mathrm{Mp}=$ Mperesso (centre zone), $\mathrm{Na}=$ Nafégué (south zone)

Variation of the length of phenological events for the different age classes within stands according to the year is displayed in Table 4 . The variability of the means between age classes within stands of each site in a given year is low. However, the variability over the years for each age class in each stand is substantial. The pattern of this variability is similar to that described above for stands (Table 3).

\section{DISCUSSION}

\section{Morphological Traits of Shea Trees According to Sites and Stands}

Morphological traits of adult shea trees varied for the measured variables. For diameter growth, even though the site effect was significant, there was no evident relationship between this significance and climatic conditions. The southern zone had the lowest mean diameter, which suggests that the effect of management practice could have a stronger impact on shea tree growth than that of climatic conditions alone. This result strengthens what has been reported by several authors about the effect of farmers' management practices influencing not only the growth of shea trees but also their spatial distribution, production and dissemination, the dynamics of its regeneration and the evolution of its genetic diversity $[14,15]$.

The effect of management practice (regulating the alternating field/fallow cycle), was also displayed through the significant difference between stands. The highest mean diameter observed for fallows over all sites and also in the centre and the north can be explained by management practices regulating land use

Table 3: Variation of the mean lengths of phenological events over the years according to stands within sites

\begin{tabular}{|c|c|c|c|c|c|c|c|c|c|c|}
\hline \multirow[b]{2}{*}{ Sites } & \multirow[b]{2}{*}{ Stands } & \multicolumn{3}{|c|}{$\begin{array}{c}\text { Means of flowering length per year (in } \\
\text { number of days) }\end{array}$} & \multicolumn{3}{|c|}{$\begin{array}{c}\text { Means of fruiting length per year (in } \\
\text { number of days) }\end{array}$} & \multicolumn{3}{|c|}{$\begin{array}{l}\text { Means of leafing length per year (in } \\
\text { number of days) }\end{array}$} \\
\hline & & 2008 & 2009 & 2010 & 2008 & 2009 & 2010 & 2008 & 2009 & 2010 \\
\hline \multirow{4}{*}{$\mathrm{Da}$} & Field & 45 & 77 & 80 & 95 & 92 & 115 & 36 & 49 & 43 \\
\hline & Fallow & 43 & 72 & 76 & 93 & 78 & 105 & 36 & 46 & 44 \\
\hline & All & 44 & 75 & 78 & 94 & 87 & 110 & 36 & 48 & 44 \\
\hline & Field & 58 & 68 & 88 & 106 & 101 & - & 32 & 33 & 47 \\
\hline \multirow[t]{3}{*}{$\mathrm{Mp}$} & Fallow & 55 & 64 & 90 & 119 & 105 & - & 36 & 35 & 44 \\
\hline & All & 56 & 66 & 89 & 113 & 103 & - & 34 & 34 & 45 \\
\hline & Field & 34 & 80 & 72 & 56 & 88 & 102 & 30 & 38 & 45 \\
\hline \multirow[t]{2}{*}{$\mathrm{Na}$} & Fallow & 28 & 80 & 81 & 49 & 89 & 105 & 33 & 54 & 48 \\
\hline & All & 33 & 80 & 76 & 53 & 88 & 103 & 31 & 46 & 46 \\
\hline
\end{tabular}

Legend: $\mathrm{Da}=$ Daelan (north zone), $\mathrm{Mp}=$ Mperesso (centre zone), $\mathrm{Na}=$ Nafégué (south zone) 
Kelly, et al.

Table 4: Variation of the mean lengths of phenological events over the years according to age classes within stands

\begin{tabular}{|c|c|c|c|c|c|c|c|c|c|c|}
\hline \multirow[t]{2}{*}{ Sites/stands } & \multirow[t]{2}{*}{ Age } & \multicolumn{3}{|c|}{$\begin{array}{c}\text { Means of flowering length per year (in } \\
\text { number of days) }\end{array}$} & \multicolumn{3}{|c|}{$\begin{array}{c}\text { Means of fruiting length per year (in } \\
\text { number of days) }\end{array}$} & \multicolumn{3}{|c|}{$\begin{array}{c}\text { Means of leafing length per year (in } \\
\text { number of days) }\end{array}$} \\
\hline & & 2008 & 2009 & 2010 & 2008 & 2009 & 2010 & 2008 & 2009 & 2010 \\
\hline \multirow[t]{3}{*}{ Da Field } & New & 48 & 77 & 81 & 97 & 92 & 113 & 33 & 49 & 45 \\
\hline & Medium & 49 & 78 & 82 & 97 & 92 & 122 & 38 & 53 & 42 \\
\hline & Old & 42 & 74 & 77 & 92 & - & 110 & 38 & 45 & 42 \\
\hline \multirow[t]{3}{*}{ Da Fallow } & New & 46 & 60 & 80 & 89 & - & 104 & 36 & 44 & 43 \\
\hline & Medium & 46 & 72 & 73 & 91 & - & 100 & 40 & 52 & 42 \\
\hline & Old & 38 & 74 & 78 & 98 & 78 & 112 & 33 & 44 & 49 \\
\hline \multirow[t]{3}{*}{ Mp Field } & New & 62 & 73 & 93 & 105 & 106 & - & 31 & 31 & 46 \\
\hline & Medium & 54 & 62 & 97 & 108 & 98 & - & 31 & 33 & 50 \\
\hline & Old & 57 & 66 & 78 & 106 & 98 & - & 36 & 36 & 46 \\
\hline \multirow[t]{3}{*}{ Mp Fallow } & New & 55 & 61 & 99 & 115 & 108 & - & 30 & 34 & 42 \\
\hline & Medium & 54 & 69 & 86 & 130 & 101 & - & 32 & 35 & 45 \\
\hline & Old & 56 & 56 & 70 & 113 & - & - & 45 & 36 & 43 \\
\hline \multirow[t]{3}{*}{$\mathrm{Na}$ Field } & New & 35 & 86 & 76 & 61 & 90 & 105 & 29 & 33 & 48 \\
\hline & Medium & 23 & 78 & 67 & 55 & 88 & 100 & 30 & 36 & 45 \\
\hline & Old & 44 & 75 & 74 & 53 & 86 & 100 & 32 & 44 & 42 \\
\hline \multirow[t]{3}{*}{ Na Fallow } & New & - & 80 & 75 & 52 & 95 & 103 & 35 & 43 & 43 \\
\hline & Medium & 28 & 82 & 80 & 41 & 81 & 103 & 29 & 59 & 49 \\
\hline & Old & - & 79 & 88 & 49 & 91 & 108 & 34 & 60 & 52 \\
\hline
\end{tabular}

Legend: $\mathrm{Da}=$ Daelan (north zone), $\mathrm{Mp}=$ Mperesso (centre zone), $\mathrm{Na}=$ Nafégué (south zone)

systems. In the centre and the north, long cultivation periods are observed because of the scarcity of arable soil, so young fallows are just old fields, which explains the highest mean diameter of these stands.

Height growth seems to be more affected by climatic conditions. The southern site (Nafégué) had the highest height, whereas the northern site (Daelan) had the lowest. This result essentially displays the climatic gradient effect. Height growth also displayed a significant mean annual increment, unlike the diameter for which the mean annual increment was very low, as reported in earlier studies of adult shea trees [16].

\section{Chronology of Phenological Activities According to Sites and Stands}

The onset of flowering, fruiting and leafing of shea trees increased in a south-north direction. For instance, phenological activities started earlier in the southern site (Nafégué) with a peak of flowering in the south corresponding to the start of flowering in the northern sites (Mperesso and Daelan), and the physical maturity of fruits (full-sized fruits) in the south corresponding to the peak of flowering in the north. This trend of variation of shea phenology along a south-north gradient was observed in previous studies $[17,18]$. It was also observed for species like P. biglobosa [19], A. digitata [20] and many other typical savannah medicinal plants including V. Paradoxa [21]. Variation according to a south-north gradient was also observed for fruit and leaf morphological traits of shea trees [22], for fat content [23] and for the chemical content of shea [24,25].

However, it is interesting to note that the time period covered by phenological activities is almost the same whatever the site. This period is five to six months for flowering and fruiting, and one to four months for leafing. A similar duration of flowering and fruiting was observed in the eastern part of the shea area (Uganda) for Vitellaria paradoxa subsp. nilotica [6]. These authors found that the flowering lasted for five to seven months and fruit maturation and ripening requires six to eight months. The long time period covered by phenological activities compared to their length confirms the existence of different categories of individuals in shea populations: precocious individuals, late individuals and in-between ones. The time period reported was counted from the start of activities of the most precocious individual to the end of the activities of the latest one.

These results suggest that phenological activities are genetically governed, their start or end being influenced by other abiotic factors, as we observed in this study and as reported for many tropical tree species [15, 26-29].

Variability in the onset of shea phenological activities according to the year was also observed. It is particularly evident for leafing for which a high variability was observed in all sites, mainly in the fallow stands at Nafégué (south). In this site (north Guinean zone), farmers still practice traditional bush burning, which affects shea trees, which react by shedding old leaves and flushing new buds. Okullo et al. [6] explained the leafing pattern observed in their study by the occurrence of fire, which they consider could have an impact on all components of the life cycle of a tree species.

The high variation of leafing might also be related to rainfall, which is very irregular in the Sahel, with alternating good and bad seasons. As adaptation strategies, depending on water shortage or availability in the soil or depending on atmospheric relative humidity, shea trees shed old leaves earlier or later, while starting to flush new buds, but with an indistinguishable transition from old to new foliage [6]. According to Borchert [30], this type of leaf development in the case of shea trees is more closely connected to changing conditions in water availability. 
Variation of the onset and end of shea tree phenological activities according to the year was reported in previous studies. Dean Anderson et al. [31] reported for 38 monitored tree species that the peak in leaf flushing varied substantially from year to year, but tended to occur between February and June. A cyclic production of the shea tree was noted in previous studies, even though the underlying factors are not yet well determined. Several factors were evoked but are not really supported by scientific findings, as the cycle is incompletely understood and varies from 2 to 3 years or more $[16,17]$.

Farmers, however, are really convinced that shea production is linked to rainfall and that in a given year fruit production depends on the rainfall of the preceding year [32]. Their belief seems to be supported by some results at least in the north and the centre, where the bad year of fruiting (2009) was preceded by one of the worst years (2008) regarding total rainfall, with $558 \mathrm{~mm}$ in the north (mean rainfall over 21 years $=699 \mathrm{~mm}$ ) and $720 \mathrm{~mm}$ in the centre (mean rainfall over 21 years = $901 \mathrm{~mm}$ ). In the south, 2009 had the lowest total rainfall with $797 \mathrm{~mm}$ (mean rainfall over 13 years $=1040 \mathrm{~mm}$ ). The level of fruiting in the fields at Nafégué in 2010 (after the low rainfall year 2009) was lower than those of 2008 and 2009.

\section{Variation Over The Years in Flowering and Fruiting Ability}

Most of the discussion we had in the previous section is strengthened by the results on flowering and fruiting ability. Regarding cyclic phenomena, over three years, we observed two years (2008 and 2010) of good fruiting and flowering in all sites and one in-between year (2009) with low flowering and fruiting, with large variation according to sites and stands. These results were in accordance with those obtained by Kelly et al. [18] who found a difference between two successive years (2004 and 2005) in the flowering ability of shea in the field at Mperesso $(100 \%$ versus 66\%). The harmony between flowering and fruiting in the fields was good in all years at Nafégué in the south, but not good in 2009 at Mperesso in the centre and Daelan in north. A higher discordance between flowering and fruiting was observed in the fallows of these last two sites. This seems to be site-dependent and the results corroborate the farmers' belief regarding shea production. The discordance between flowering and fruiting for tree species was reported by Dean Anderson et al., [31] in a study of factors influencing tree phenology in Taï National Park (Côte d'Ivoire). These authors stated that there were multiple instances where flowering activities were not followed by fruiting activities.

\section{Length of Phenological Activities}

A significant difference was found between sites and between stands within sites. Some large coefficients of variation were observed, particularly for leafing, indicating high variability of the length of this phenological event, the only one displaying significant differences between stands. There was no particular trend displaying a climatic gradient effect; the differences observed varied according to variables and displayed very mixed similarities or dissimilarities between sites and stands.
The duration of shea tree phenological activities is likely to be influenced by other biotic or abiotic factors not explicitly taken into account in this study. These factors might occur before the onset of activities (in the short or long term) or while activities are ongoing. Ruyssen [16] suggested a possible effect of relative humidity, temperature, wind and fire. Okullo et al. [6] found that flowering and fruiting intensities were negatively correlated with both mean monthly rainfall and monthly rainfall total and positively correlated with monthly means of daily maximum temperature. In their study of factors influencing tree phenology, Dean Anderson et al. [31] listed the all the variables related to the environment like temperature, rainfall and their relation in determinng the phenology. The observed ranges of phenological activities were, however, in accordance with those observed in previous studies for shea trees $[6,18]$ as well as for other tropical tree species [31]. For instance, Oni et al. [29] observed for $\mathrm{V}$. paradoxa in Nigeria $45.68 \pm 3.77$ days as the mean number of days to flowering and $145.87 \pm 7.86$ days as the mean fruit set period.

\section{CONCLUSION}

Our results are in agreement with previous findings and reflect the interacting biotic and abiotic factors influencing shea tree vegetative and productive phenologies. In many respects, the centre (Mperesso) and the north (Daelan) were similar, and on several occasions they contrasted with the south (Nafégué). Similar results were found in fat content, fatty acid composition and tocopherol content. As far as the shea tree is concerned, the two sites (Mperesso and Daelan) might constitute the same agro-ecological zone or should be taken as such, since they are not geographically very distant from each other. Therefore, it would be better to monitor the phenology in the extreme north in the districts of Bankass or Bandiagara as it was done for molecular and chemical studies. Our findings could provide a good guide for germplasm collection (seed harvesting) according to zones. Also, in highlighting the involvement of management practices in the phenological activities of shea trees, our findings could help in the genetic improvement of the species and in the development of strategies for its domestication.

\section{ACKNOWLEDGEMENTS}

We are very grateful to the European Union for funding the INNOVKAR project. Many thanks to the field technicians Sabéré Coulibaly, Sékou Coulibaly, Idrissa Poudiougou and Ousmane Sanogo who worked hard in collecting phenological data and to all other colleagues at the Forestry Resources Programme. Many thanks also to the Daelan, Mperesso and Nafégué village authorities and populations for allowing us to conduct this study on their land and parcels and for cooperating infield activities.

\section{REFERENCES}

1. De Bie S., Ketner P., Paasse M. and Geerling C. Woody plant phenology in West Africa savanna. Journal of Biogeography 1998; 25: 883-900

2. De Bie S. Wildlife resources of the West African Savanna. Phd-Thesis. 
Kelly, et al.

Wageningen Agric. University papers 1991; 91-2: 1-127

3. Sun C., Kaplin B.A., Krostensen A.K., Munyaligago V., Vukiyumwami J., Kanyonyo K.K. and Moermond T.C. Tree phenology in a tropical montane forest in Rwanda. Biotropica 1996; 28: 668-681

4. Machado L.C.S., Barros L.M. and Sampaio E.V.S.B. Phenology of Caatinga species at Serra Tahada, PE, north-eastern Brazil. Biotropica 1997; 29: 57-68

5. Lieth H. Phenology and seasonality modelling. Springer-Verlag, Berlin 1974

6. Okullo J.B.L., Hall J.B. and Obua J. Leafing, flowering and fruiting of Vitellaria paradoxa subsp. nilotica in savannah parklands in Uganda. Agroforestry Systems 2004; 60: 77-91

7. Gessner U., Knauer K., Kuenzer C., Dech S. Land Surface Phenology in a West African Savanna: Impact of Land Use, Land Cover and Fire. In: Kuenzer C., Dech S., Wagner W. (eds) Remote Sensing Time Series. Remote Sensing and Digital Image Processing. Springer, Cham 2015; vol 22

8. Sarmiento G. Et Monasterio M. Life forms and phenology. Tropical savannas (ed. By F. Bourlière). Ecosystems of the world. Elsevier, Amsterdam 1983; 13

9. Goulart M.F., Filho J.P.L., and Lovato M.B. Phenological variation within and among Populations of Plathymenia reticulata in Brazilian Cerrado, the Atlantic Forest and Transitional Sites. Annals of Botany 2005; 96: 445-455

10. Okullo J.B.L., Hall J.B. and Masters E. Reproductive biology and breeding systems of Vitellaria paradoxa. In: Improved management of agroforestry parkland systems in Sub-Saharan Africa, EU/INCO Project Contract IC18-CT98-0261, Final report, University of Wales Bangor, UK 2003; p. 66-84

11. Nikiema A., van der Maesen L.J.G. and Hall J.B. The impact of parkland management practices on plant resources diversity. In: Improved management of agroforestry parkland systems in Sub-Saharan Africa, EU/INCO Project Contract IC18-CT98-0261, Final report, University of Wales Bangor, UK 2003; p. 43-50

12. Maïga A.Y. Action thématique sur la mortalité du karité Butyrospermum paradoxum (Gaertner f) Hepper dans la région de Ségou - phase de prolongation: actualisation des chiffres de densité de karité au Mali. Rapport final de prolongation DRFH/INRZFH Sotuba, Mali 1988; 48 p

13. Boussim J., Odebiyi A., Kambou S. and Salle G. The ecology and biology of parasites and pests of parkland trees and their control methods. n: Improved management of agroforestry parkland systems in Sub-Saharan Africa, EU/INCO Project Contract IC18-CT98-0261, Final report, University of Wales Bangor, UK2003.p. 113-130

14. Kessler J.J. and Boni J. L'agroforesterie au Burkina Faso. Bilan et analyse de la situation actuelle. Tropical resources management Papers. N¹. ED. MET-U. Wageningen 1991; 144p

15. Kelly B.A. Impact des pratiques humaines sur la dynamique des populations et sur la diversité génétique de Vitellaria paradoxa (karité) dans les systèmes agroforestiers au sud du Mali. Thèse de doctorat. Université de Bamako 2005; 243 p

16. Ruyssen B. Le Karité au soudan. Agronomie Tropicale 1957; 12: 143-289

17. Hall J.B., Aebischer D.P., Tomlinson H.F., Osei-amaning E. and Hindle J.R. Vitellaria paradoxa. A monograph. School of Agricultural and Forest Sciences Publication Number: 8, University of Wales,
Bangor 1996; $105 \mathrm{p}$

18. Kelly B.A., Gourlet-Fleury S., and Bouvet J-M. Impact of Agroforestry Practices on the Flowering Phenology of Vitellaria paradoxa in parklands in Southern Mali. AgroforestrySystems2007; 7: 67-75

19. Oni, P.I. Breeding systems in Parkia biglobosa (Jacq.) Benth; an indigenous fruit resource utilization in Nigeria. Journal of Tropical Resources2001; 17: 1-9

20. Oni P.I., Attah, V.I., Awosan A.O. and Sobola, O.O. A tool-kit in germplasm conservation and domestication of Adansonia digitata Lin in Nigeria. Direct Research Journal of Agriculture and Food Science 2016; Vol. 4 (11): 308-313

21. Oni P.I., Jimoh S.O. and Adebesi L.A. Population pattern and phenological behaviours for selected medicinal plants in Nigeria; implications for ex-situ conservation. Journal of Applied pharmaceutical Science 2013; Vol. 3 (07): 052-060

22. Sanou H. Domestication and pre-breeding of shea tree: characterisation, mobilisation of local varieties by a multitrait and participative approach and horticultural research. Research periodic report for the INNOVKAR project 2008

23. Davrieux F. and Piombo G. Variation of pattern in fatty acid and tocopherol in population of Mali and Uganda - Preliminary Report. Research periodic report for the INNOVKAR project presented at the Innovkar steering committee at Tamale (Ghana) 2008. 23p

24. Maranz S., Wiesman Z., Bisgaard J., Bianchi G. Germplasm resources of Vitellaria paradoxa based on variations in fat composition across the species distribution range. Agroforestry Systems2004; 60: 71-76

25. Davrieux F., Allal F., Piombo G., Kelly B., Okullo J.B., Thiam M., Diallo O.B., and Bouvet J-M. Near Infrared Spectroscopy for HighThroughput Characterization of Shea Tree (Vitellaria paradoxa) Nut Fat Profiles. Journal of Agricultural and Food Chemistry2010; 58: 7811-7819

26. Law B., Mackowski C., Choer C.L. and Tweedie T. Flowering phenology of myrtaceous trees and their relation to climatic, environmental and disturbance variables in northern New South Wales. Austral Ecology 2000:25: 160-178

27. Nomura N. and Kikuzawa K. Productive phenology of tropical montane forests: Fertilization experiments along a moisture gradient. Ecological Research 2003; 18: 573-585.

28. Badeck F.W., Bondeau A., Böttcher K., Doktor D., Lucht W., Schaber J. and Sitch S. Responses of spring phenology to climate change. New Phytologist 2004; 162: 295-309

29. Oni P.I., Jimoh S.O. and Adebesi L.A. Mangement of indigeneous plants in Nigeria using phenological information. Journal of Medecina Plant Research 2014; Vol. 8 (16): 619-631

30. Borchert R. Water status and development of tropical trees during seasonal drought. Trees 1994; 8: 115-125

31. Dean Anderson P., Nordheim E.V., Moermond T.C., Gone Bi Z.B., and Boesch C. Factors influencing tree phenology in Taï National Park, Côte d'Ivoire. Biotropica 2005; 37(4): 631-640

32. Kelly B.A., Yossi H. et Senou O. Enrichissement des parcs à karité (Vitellaria paradoxa Gaertn.F.) en zone soudanienne au Mali: Identification et caractérisation agromorphologique des karités performants. Rapport d'Etude, Convention IER-CRRA/ Sikasso - Programme d'Appui aux Filières Agricoles (PAFA) 2011 